\title{
Induction of Epoxide Hydrolase, Glucuronosyl Transferase, and Sulfotransferase by Phenethyl Isothiocyanate in Male Wistar Albino Rats
}

\author{
Ahmad Faizal Abdull Razis, ${ }^{1}$ Noramaliza Mohd Noor, ${ }^{2}$ and Nattaya Konsue ${ }^{3}$ \\ ${ }^{1}$ Food Safety Research Centre (FOSREC), Faculty of Food Science and Technology, Universiti Putra Malaysia, \\ 43400 Serdang, Selangor Darul Ehsan, Malaysia \\ ${ }^{2}$ Department of Imaging, Faculty of Medicine and Health Sciences, Universiti Putra Malaysia, 43400 Serdang, Selangor, Malaysia \\ ${ }^{3}$ School of Agro-Industry, Mae Fah Luang University, 333 Moo1 Thasud Muang, Chiang Rai 57100, Thailand \\ Correspondence should be addressed to Ahmad Faizal Abdull Razis; madfaizal@upm.edu.my
}

Received 12 September 2013; Revised 2 November 2013; Accepted 2 November 2013; Published 27 January 2014

Academic Editor: Lillian Barros

Copyright (C) 2014 Ahmad Faizal Abdull Razis et al. This is an open access article distributed under the Creative Commons Attribution License, which permits unrestricted use, distribution, and reproduction in any medium, provided the original work is properly cited.

Phenethyl isothiocyanate (PEITC) is an isothiocyanate found in watercress as the glucosinolate (gluconasturtiin). The isothiocyanate is converted from the glucosinolate by intestinal microflora or when contacted with myrosinase during the chopping and mastication of the vegetable. PEITC manifested protection against chemically-induced cancers in various tissues. A potential mechanism of chemoprevention is by modulating the metabolism of carcinogens so as to promote deactivation. The principal objective of this study was to investigate in rats the effect of PEITC on carcinogen-metabolising enzyme systems such as sulfotransferase (SULT), N-acetyltransferase (NAT), glucuronosyl transferase (UDP), and epoxide hydrolase (EH) following exposure to low doses that simulate human dietary intake. Rats were fed for 2 weeks diets supplemented with PEITC at $0.06 \mu \mathrm{mol} / \mathrm{g}$ (low dose, i.e., dietary intake), $0.6 \mu \mathrm{mol} / \mathrm{g}$ (medium dose), and $6.0 \mu \mathrm{mol} / \mathrm{g}$ (high dose), and the enzymes were monitored in rat liver. At the Low dose, no induction of the SULT, NAT, and EH was noted, whereas UDP level was elevated. At the Medium dose, only SULT level was increased, whereas at the High dose marked increase in EH level was observed. It is concluded that PEITC modulates carcinogen-metabolising enzyme systems at doses reflecting human intake thus elucidating the mechanism of its chemoprevention.

\section{Introduction}

Phenethyl isothiocyanate (PEITC) is a phytochemical with an aromatic side chain, found in cruciferous vegetables such as watercress, where it is present as a glucosinolate, so called gluconasturtiin [1]. Whenever this vegetable is interrupted, for instance during mastication, the enzyme myrosinase ( $\beta$-thioglucoside glucohydrolase) is released and induce the conversion of gluconasturtiin into PEITC as well as in the human intestine by microbial myrosinase [2]. Epidemiological studies reported an inverse association between cruciferous vegetable consumption and risk of cancers including lung [3], colorectal [4], and breast [5] cancers, all common cancers, mainly in developed and developing countries.
In animal-induced cancer model studies, PEITC has been reported to antagonise the carcinogenicity of chemicals in various tissues $[6,7]$. It has exhibited a protection on chemically-induced carcinogenesis in the oesophagus, intestine, lung, and pancreas induced by azoxymethane, nitrosocompounds, and polycyclic aromatic hydrocarbons $[6,8-$ $10]$, even though no beneficial effect was observed in colon cancer-induced by azoxymethane when the formation of aberrant crypt foci was used as biomarker [11]. Interestingly, the mercapturate of PEITC, an important metabolite, preserves its chemopreventive properties [12].

PEITC elicits its chemoprevention by blocking initiation [13] and post-initiation processes of tumour growth via modulating proliferation of cells cycle and induction of apoptosis [14-16]. Protecting against DNA damage and, thus, 
suppressing tumour initiation step is a major importance anticarcinogenic mechanism of isothiocyanates [17]. This can be achieved by reducing the availability of the metabolite products of chemical carcinogens by averting their generation, thus inhibition of their cytochrome P450-mediated bio-activation [18-20], and/or by stimulating their detoxification, via induction of enzyme systems such as the quinone reductase and glutathione $S$-transferases [21]. Nevertheless, the chemopreventive properties of isothiocyanates at this stage are multiple depending on dose regimen, animal species [22], nature of isothiocyanate [23], target tissue [24], and treatment protocol [25].

In studies employing precision-cut liver slices, the ability of PEITC to modulate carcinogen-metabolising enzymes in rat and human liver has been established $[26,27]$ and as a result revealed its potency to function as an anticancer agent. It is important to assess whether carcinogen metabolising enzymes react similarly to PEITC in animal models in vivo following exposure to low doses that simulate human dietary intake.

Most studies have focussed on quinone reductase and the glutathione $S$-transferases, and the modulation of other major carcinogen-metabolising hepatic enzyme systems by PEITC still remains to be evaluated. The objective of the current study was to evaluate in rats the effect of PEITC intake, employing dietary levels of exposure, on carcinogen metabolising enzymes systems, for example, epoxide hydrolase, glucuronosyl transferase, sulfotransferase, and $\mathrm{N}$ acetyltransferase. Modulation of carcinogen metabolising enzymes was investigated in a liver tissue, as the liver is the principal site of the bioactivation of carcinogens [28]. A marked induction of epoxide hydrolase was observed at the high dose, while at the low and medium doses, glucuronosyl transferase and sulfotransferase levels were elevated, respectively.

\section{Materials and Methods}

Phenethyl isothiocyanate (PEITC) (LKT Laboratories, MN, USA), benzo[a]pyrene 4,5-epoxide and benzo[a]pyrene 4,5diol (Mid-West Research Institute, KS, USA), 1-naphthol, 2naphthol, and 4-aminobenzoic acid (Sigma Co. Ltd., Poole, Dorset, UK) were all purchased.

Male Wistar albino rats $(180 \pm 20 \mathrm{~g})$ were obtained from B\&K Universal Ltd (Hull, East Yorkshire, UK). The animals were housed at $22 \pm 2^{\circ} \mathrm{C}, 30-40 \%$ relative humidity, in an alternating $12 \mathrm{~h}$ light: dark cycle with light onset at $07.00 \mathrm{~h}$. After a week's acclimatization, the rats were randomly assigned into 4 groups of 5 rats each. Animal doses were chosen so that the low dose responses the average human daily intake of glucosinolates $(75 \mathrm{mg} /$ person/day or $1.07 \mathrm{mg} / \mathrm{kg}$ bw) [29]. Three groups were administered diets supplemented with 0.06 (low dose), 0.6 (medium dose), and 6.0 (high dose) $\mu \mathrm{mol}$ PEITC/g diet, whereas one group served as control; animals were maintained on these diets for 14 days. At the end of the treatment period, rats were sacrificed and the livers were removed. Tissue samples were immediately frozen in liquid nitrogen and stored at $-80^{\circ} \mathrm{C}$ until required.
Hepatic S9 of liver $(25 \% \mathrm{w} / \mathrm{v})$, in $0.154 \mathrm{M} \mathrm{KCl}$ containing $50 \mathrm{mM}$ Tris- $\mathrm{HCl}, \mathrm{pH} 7.4$, was prepared prior to microsomal and cytosolic separation by differential centrifugation. The following assays were carried out on isolated microsomes: glucuronosyl transferase (UDP) using 1-naphthol as substrate [30], epoxide hydrolase (EH) using benzo[a]pyrene 4,5epoxide [31] as well as on the isolated cytosols, that is, sulfotransferase (SULT) using 2-naphthol as substrate [32], and $\mathrm{N}$-acetyltransferase (NAT) using 4-aminobenzoic acid [33]; protein concentration was determined in both cellular subfractions using bovine serum albumin as standard [34].

Results are presented as mean \pm standard deviation of groups of five rats each. Statistical evaluation was carried out by one-way ANOVA followed by the Dunnett's test.

\section{Results and Discussion}

The present study investigated the in vivo modulation of carcinogen-metabolising enzymes by PEITC, as this emerged as an impressing chemoprevention mechanism in the studies employing precision-cut rat [26] and human liver slices [27]. Rats were treated with diets supplemented with 3 different doses, 0.06 (low dose), 0.6 (medium dose), and 6.0 (high dose) $\mu \mathrm{mol} \mathrm{PEITC/g}$ diet for 14 days. The low dose is proportionate with human dietary intake of total glucosinolates, $75.5 \mathrm{mg} /$ person/day or $1.07 \mathrm{mg} / \mathrm{kg}$ body weight for a $70 \mathrm{~kg}$ individual [29], which is comparable to an intake of $300 \mathrm{~g}$ watercress, the primary source of PEITC, based on $100 \mathrm{~g}$ watercress releasing approximately $25 \mathrm{mg}$ PEITC [35]. Earlier studies in animal models have utilised either a single high dose or chronic intake of higher doses than those employed in the current study $[36,37]$. Studies were carried out in the liver as it the principal site of bioactivation of chemical carcinogens [28].

Even though the effects of isothiocyanates on quinone reductase and glutathione $S$-transferases have been well reported both in vitro and in vivo, their capability to modulate other phase II enzyme systems involved in carcinogen metabolism has received little attention. Glucuronosyl transferases are a very essential phase II detoxifying enzyme system involved in the metabolism of chemical carcinogens including aromatic amines and polycyclic aromatic hydrocarbons [38]. The current studies found that PEITC at the low dose has the potential to upregulate glucuronosyl transferase (Figure 1), which commensurate previous findings where cruciferous vegetable consumption led to increased glucuronidation of the heterocyclic amine PhIP (2-amino1-methyl-6-phenylimidazo [4,5-b]pyridine) in human volunteers, even though other components in the vegetables are likely to have also contributed to the upregulation of this enzyme [39]. Similarly, the consumption of diets supplemented with cruciferous vegetables reduced serum bilirubin levels, the glucuronidation that was catalysed by glucuronosyl transferase 1A1 (UGT1A1) [40]. In addition, PEITC isolated from watercress enhanced the metabolism of nicotine due to increased glucuronidation among smokers [41], while in rat liver slices, PEITC led to increase in the glucuronidation of 1-naphthol [26]. 


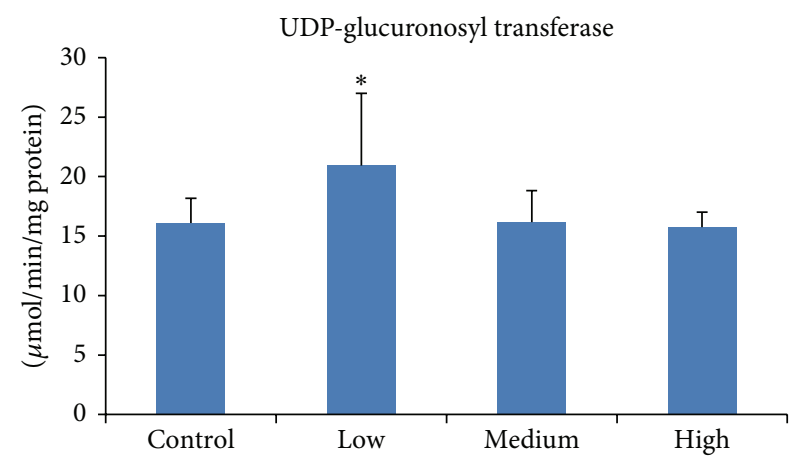

FIGURE 1: Effect of PEITC on glucuronosyl transferase activity in rat liver. Groups of five rats were exposed to diets supplemented with PEITC at 0.06 (low dose), 0.6 (medium dose), and 6.0 (high dose) $\mu \mathrm{mol} / \mathrm{g}$ diet for 14 days, whereas another group served as control. At the end of the treatment period, hepatic $S 9$ was prepared from which microsomes were isolated and used to determine glucuronosyl transferase activity. Results are presented as mean \pm SD for five rats. ${ }^{*} P<0.05$.

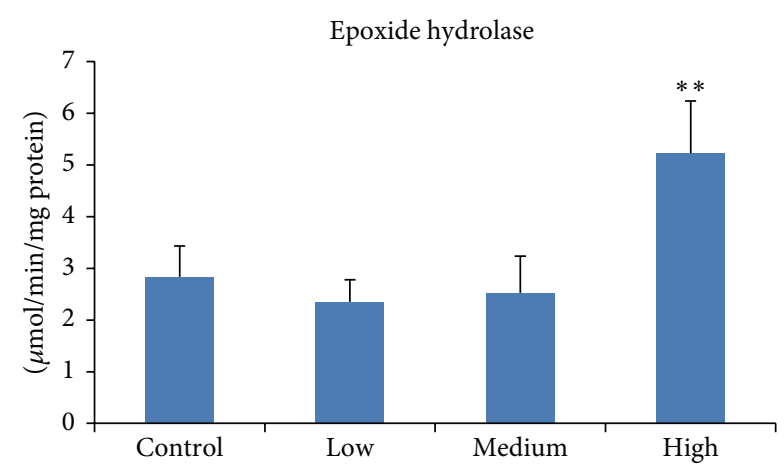

FIGURE 2: Effect of PEITC on epoxide hydrolase activity in rat liver. Groups of five rats were exposed to diets supplemented with PEITC at 0.06 (low dose), 0.6 (medium dose), and 6.0 (high dose) $\mu \mathrm{mol} / \mathrm{g}$ diet for 14 days, whereas another group served as control. At the end of the treatment period, hepatic S9 was prepared from which microsomes were isolated and used to determine epoxide hydrolase activity. Results are presented as mean \pm SD for five rats. ${ }^{* *} P<0.01$.

Epoxide hydrolase is the phase II enzyme involved in the detoxification of many epoxides, the reactive intermediates of chemical carcinogens including polycyclic aromatic hydrocarbons, aflatoxin B1, and halogenated aliphatic compounds [42]. The present study showed that at the high dose PEITC elevated epoxide hydrolase (Figure 2), in concordance with our previous findings [26]; an 8 -fold rise in the activity was exhibited, rendering it one of the potent inducers of this enzyme.

Sulfotransferases are the enzymes that catalyse sulfonation, an important reaction involved in the metabolism of numerous xenobiotics, drugs, and endogenous compounds [43]. The process of sulfonation encompasses the transfer of a sulfonyl $\left(\mathrm{SO}_{3}{ }^{-}\right)$group, normally to a hydroxyl on an acceptor molecule, which is catalysed by sulfotransferases [44]. It was revealed that medium dose of PEITC increased the level of this enzyme indicating that

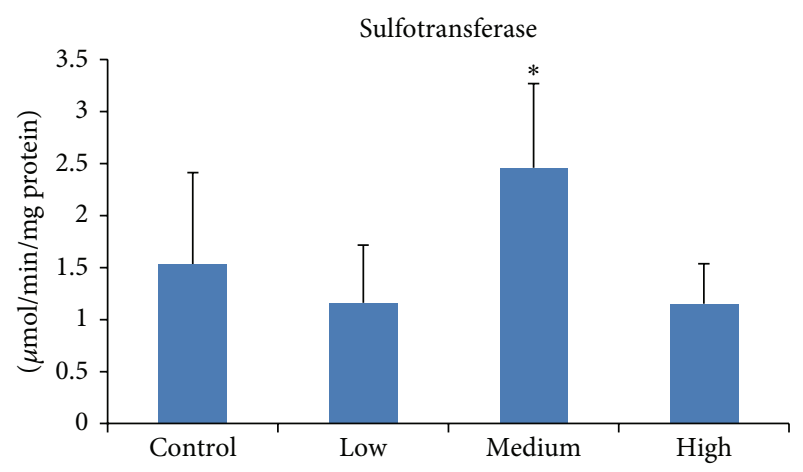

FIgURE 3: Effect of PEITC on sulfotransferase activity in rat liver. Groups of five rats were exposed to diets supplemented with PEITC at 0.06 (low dose), 0.6 (medium dose), and 6.0 (high dose) $\mu \mathrm{mol} / \mathrm{g}$ diet for 14 days, whereas another group served as control. At the end of the treatment period, hepatic S9 was prepared, and then cytosol was isolated and used to determine sulfotransferase activity. Results are presented as mean $\pm \mathrm{SD}$ for five rats. ${ }^{*} P<0.05$.

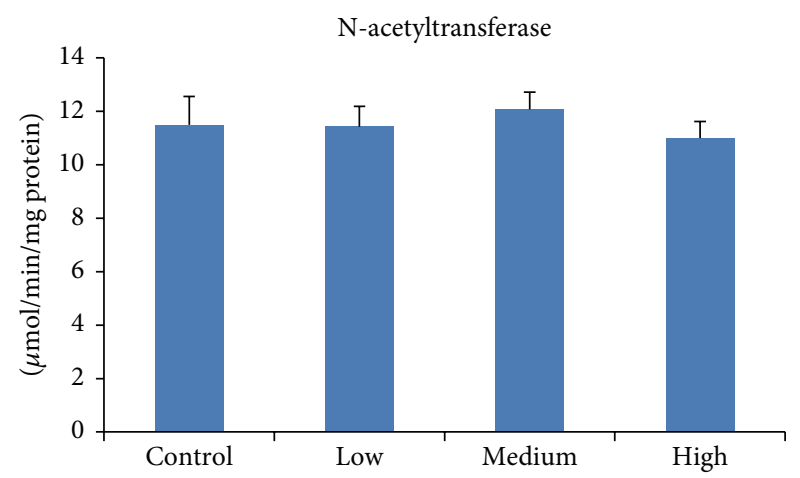

FIGURE 4: Effect of PEITC on N-acetyltransferase activity in rat liver. Groups of five rats were exposed to diets supplemented with PEITC at 0.06 (low dose), 0.6 (medium dose), and 6.0 (high dose) $\mu \mathrm{mol} / \mathrm{g}$ diet for 14 days, whereas another group served as control. At the end of the treatment period, hepatic S9 was prepared and then cytosol was isolated and used to determine $\mathrm{N}$-acetyltransferase activity. Results are presented as mean \pm SD for five rats.

PEITC accepting sulfonyl group to its hydroxyl (Figure 3). $\mathrm{N}$-acetyltransferases are cytosolic conjugating enzymes which transfer an acetyl group from acetyl coenzyme A to a xenobiotic acceptor substrate [45]. Our finding showed that this enzyme was unaffected (Figure 4), elucidating that acetyl group was transferred to PEITC forming $\mathrm{N}$-acetylcysteine (NAC) conjugate of phenethyl isothiocyanate (PEITC-NAC), the major metabolite of PEITC that is abundant in watercress [46].

\section{Conclusions}

The present studies allow us to infer that phenethyl isothiocyanate modulates carcinogen-metabolising enzyme systems at doses reflecting human intake as a marked induction of epoxide hydrolase which was seen at the high dose, while at the low and medium doses, glucuronosyl transferase 
and sulfotransferase levels were upregulated, respectively. Increased levels of detoxification enzymes such as epoxide hydrolase, glucuronosyl transferase, and sulfotransferase are the likely one of the mechanisms for chemoprevention of PEITC.

\section{Conflict of Interests}

The authors declare that there is no conflict of interests.

\section{Acknowledgment}

The authors would like to thank the Ministry of Education, Malaysia, for providing a research fund.

\section{References}

[1] A. Steinbrecher and J. Linseisen, "Dietary intake of individual glucosinolates in participants of the EPIC-Heidelberg cohort study," Annals of Nutrition and Metabolism, vol. 54, no. 2, pp. 87-96, 2009.

[2] R. Verkerk, M. Schreiner, A. Krumbein et al., "Glucosinolates in Brassica vegetables: the influence of the food supply chain on intake, bioavailability and human health," Molecular Nutrition and Food Research, vol. 53, no. 2, pp. S219-S265, 2009.

[3] K. L. Tram, L. Gallicchio, K. Lindsley et al., "Cruciferous vegetable consumption and lung cancer risk: a systematic review," Cancer Epidemiology Biomarkers and Prevention, vol. 18, no. 1, pp. 184-195, 2009.

[4] M. Epplein, L. R. Wilkens, M. Tiirikainen et al., "Urinary isothiocyanates; glutathione S-transferase M1, T1, and P1 polymorphisms; and risk of colorectal cancer: the multiethnic cohort study," Cancer Epidemiology Biomarkers and Prevention, vol. 18, no. 1, pp. 314-320, 2009.

[5] C. B. Ambrosone, S. E. McCann, J. L. Freudenheim, J. R. Marshall, Y. Zhang, and P. G. Shields, "Breast cancer risk in premenopausal women is inversely associated with consumption of broccoli, a source of isothiocyanates, but is not modified by GST genotype," Journal of Nutrition, vol. 134, no. 5, pp. 11341138, 2004.

[6] G. D. Stoner, D. T. Morrissey, Y.-H. Heur, E. M. Daniel, A. J. Galati, and S. A. Wagner, "Inhibitory effects of phenethyl isothiocyanate on $\mathrm{N}$-nitrosobenzylmethylamine carcinogenesis in the rat esophagus," Cancer Research, vol. 51, no. 8, pp. 20632068, 1991.

[7] S. S. Hecht, F.-L. Chung, J. P. Richie Jr. et al., "Effects of watercress consumption on metabolism of a tobacco-specific lung carcinogen in smokers," Cancer Epidemiology Biomarkers and Prevention, vol. 4, no. 8, pp. 877-884, 1995.

[8] F.-L. Chung, C. C. Conaway, C. V. Rao, and B. S. Reddy, "Chemoprevention of colonic aberrant crypt foci in Fischer rats by sulforaphane and phenethyl isothiocyanate," Carcinogenesis, vol. 21, no. 12, pp. 2287-2291, 2000.

[9] S. S. Hecht, N. Trushin, J. Rigotty et al., "Complete inhibition of 4-(methylnitrosamino)-1-(3-pyridyl)-1-butanone- induced rat lung tumorigenesis and favorable modification of biomarkers by phenethyl isothiocyanate," Cancer Epidemiology Biomarkers and Prevention, vol. 5, no. 8, pp. 645-652, 1996.

[10] A. Nishikawa, F. Furukawa, C. Uneyama et al., "Chemopreventive effects of phenethyl isothiocyanate on lung and pancreatic tumorigenesis in $\mathrm{N}$-nitrosobis(2-oxopropyl)aminetreated hamsters," Carcinogenesis, vol. 17, no. 6, pp. 1381-1384, 1996.

[11] A. Y. A. Plate and D. D. Gallaher, "Effects of indole-3-carbinol and phenethyl isothiocyanate on colon carcinogenesis induced by azoxymethane in rats," Carcinogenesis, vol. 27, no. 2, pp. 287292, 2006.

[12] F.-L. Chung, "Chemoprevention of lung cancer by isothiocyanates and their conjugates in A/J mouse," Experimental Lung Research, vol. 27, no. 3, pp. 319-330, 2001.

[13] Y. Zhang, "Cancer-preventive isothiocyanates: measurement of human exposure and mechanism of action," Mutation Research, vol. 555, no. 1-2, pp. 173-190, 2004.

[14] K. Xu and P. J. Thornalley, "Involvement of glutathione metabolism in the cytotoxicity of the phenethyl isothiocyanate and its cysteine conjugate to human leukaemia cells in vitro," Biochemical Pharmacology, vol. 61, no. 2, pp. 165-177, 2001.

[15] M. C. Myzak, P. A. Karplus, F.-L. Chung, and R. H. Dashwood, "A novel mechanism of chemoprotection by sulforaphane: inhibition of histone deacetylase," Cancer Research, vol. 64, no. 16, pp. 5767-5774, 2004.

[16] C. C. Conaway, C.-X. Wang, B. Pittman et al., "Phenethyl isothiocyanate and sulforaphane and their $\mathrm{N}$-acetylcysteine conjugates inhibit malignant progression of lung adenomas induced by tobacco carcinogens in A/J mice," Cancer Research, vol. 65, no. 18, pp. 8548-8557, 2005.

[17] G. Boysen, P. M. J. Kenney, P. Upadhyaya, M. Wang, and S. S. Hecht, "Effects of benzyl isothiocyanate and 2-phenethyl isothiocyanate on benzo[a]pyrene and 4-(methylnitrosamino)-1-(3pyridyl)-1-butanone metabolism in F-344 rats," Carcinogenesis, vol. 24, no. 3, pp. 517-525, 2003.

[18] C. R. Morris, S. C. Chen, L. Zhou, L. M. Schopfer, X. Ding, and S. S. Mirvish, "Inhibition by allyl sulfides and phenethyl isothiocyanate of methyl-n-pentylnitrosamine depentylation by rat esophageal microsomes, human and rat CYP2E1, and rat CYP2A3," Nutrition and Cancer, vol. 48, no. 1, pp. 54-63, 2004.

[19] M. Nakajima, R. Yoshida, N. Shimada, H. Yamazaki, and T. Yokoi, "Inhibition and inactivation of human cytochrome P450 isoforms by phenethyl isothiocyanate," Drug Metabolism and Disposition, vol. 29, no. 8, pp. 1110-1113, 2001.

[20] P. Talalay and J. W. Fahey, "Phytochemicals from cruciferous plants protect against cancer by modulating carcinogen metabolism," Journal of Nutrition, vol. 131, no. 11, pp. 3027S3033S, 2001.

[21] N. Konsue and C. Ioannides, "Modulation of carcinogenmetabolising enzyme systems in the liver and lung of rats treated with dietary doses of phenethyl isothiocyanate (PEITC)," Toxicology Letters, vol. 180, pp. S32-S246, 2008.

[22] N. Hanlon, N. Coldham, M. J. Sauer, and C. Ioannides, "Upregulation of the CYP1 family in rat and human liver by the aliphatic isothiocyanates erucin and sulforaphane," Toxicology, vol. 252, no. 1-3, pp. 92-98, 2008.

[23] S. S. Hecht, P. M. J. Kenney, M. Wang, N. Trushin, and P. Upadhyaya, "Effects of phenethyl isothiocyanate and benzyl isothiocyanate, individually and in combination, on lung tumorigenesis induced in $\mathrm{A} / \mathrm{J}$ mice by benzo[a]pyrene and 4(methylnitrosamino)-1-(3-pyridyl)-1-butanone," Cancer Letters, vol. 150, no. 1, pp. 49-56, 2000. 
[24] M. E. Staretz, L. A. Koenig, and S. S. Hecht, "Effects of long term dietary phenethyl isothiocyanate on the microsomal metabolism of 4-(methylnitrosamino)-1-(3-pyridyl)-1butanone and 4-(methylnitrosamino)-1-(3-pyridyl)-1-butanol in F344 rats," Carcinogenesis, vol. 18, no. 9, pp. 1715-1722, 1997.

[25] A. M. Pintao, M. S. S. Pais, H. Coley, L. R. Kelland, and I. R. Judson, "In vitro and in vivo antitumor activity of benzyl isothiocyanate: a natural product from Tropaeolum majus," Planta Medica, vol. 61, no. 3, pp. 233-236, 1995.

[26] A. F. Abdull Razis, M. Bagatta, G. R. De Nicola, R. Iori, and C. Ioannides, "Induction of epoxide hydrolase and glucuronosyl transferase by isothiocyanates and intact glucosinolates in precision-cut rat liver slices: importance of side-chain substituent and chirality," Archives of Toxicology, vol. 85, no. 8, pp. 919-927, 2011.

[27] N. Konsue and C. Ioannides, "Influence of phenethyl isothiocyanate (PEITC) on carcinogen metabolising enzymes in human liver: studies with precision cut slices," Toxicology Letters, vol. 180, pp. S32-S246, 2008.

[28] K. I. Eklind, M. A. Morse, and F.-L. Chung, "Distribution and metabolism of the natural anticarcinogen phenethyl isothiocyanate in A/J mice," Carcinogenesis, vol. 11, no. 11, pp. 20332036, 1990.

[29] K. Sones, R. K. Heaney, and G. R. Fenwick, "An estimate of the mean daily intake of glucosinolates from cruciferous vegetables in the UK," Journal of the Science of Food and Agriculture, vol. 35, pp. 712-720, 1984.

[30] K. W. Bock and I. N. H. White, "UDP glucuronyltransferase in perfused rat liver and in microsomes: influence of phenobarbital and 3 methylcholanthrene," European Journal of Biochemistry, vol. 46, no. 3, pp. 451-459, 1974.

[31] P. M. Dansette, G. C. DuBois, and D. M. Jerina, "Continuous fluorometric assay of epoxide hydrase activity," Analytical Biochemistry, vol. 97, no. 2, pp. 340-345, 1979.

[32] R. D. Sekura, M. W. Duffel, and W. B. Jakoby, "Aryl sulfotransferases," Methods in Enzymology, vol. 77, no. C, pp. 197-206, 1981.

[33] S. S. Mattano and W. W. Weber, "NAT activity is determined with the spectrophotometric assay using AF and PABA as substrates," Carcinogenesis, vol. 8, pp. 133-137, 1987.

[34] M. M. Bradford, "A rapid and sensitive method for the quantitation of microgram quantities of protein utilizing the principle of protein dye binding," Analytical Biochemistry, vol. 72, no. 1-2, pp. 248-254, 1976.

[35] D. Jiao, C. C. Conaway, M.-H. Wang, C. S. Yang, W. Koehl, and F.-L. Chung, "Inhibition of N-nitrosodimethylamine demethylase in rat and human liver microsomes by isothiocyanates and their glutathione, L-cysteine, and $\mathrm{N}$ - acetyl-L-cysteine conjugates," Chemical Research in Toxicology, vol. 9, no. 6, pp. 932-938, 1996.

[36] T. J. Smith, Z. Guo, C. Li, S. M. Ning, P. E. Thomas, and C. S. Yang, "Mechanisms of inhibition of 4-(methylnitrosamino)1-(3-pyridyl)-1-butanone bioactivation in mouse by dietary phenethyl isothiocyanate," Cancer Research, vol. 53, no. 14, pp. 3276-3282, 1993.

[37] M. M. Manson, H. W. L. Ball, M. C. Barrett et al., "Mechanism of action of dietary chemoprotective agents in rat liver: induction of phase I and II drug metabolizing enzymes and aflatoxin B1 metabolism," Carcinogenesis, vol. 18, no. 9, pp. 1729-1738, 1997.

[38] K. W. Bock, "UDP-Glucuronosyltransferases," in Enzyme Systems that Metabolise Drugs and Other Xenobiotics, C. Ioannides, Ed., pp. 281-318, John Wiley \& Sons, Chichester, UK, 2006.
[39] D. G. Walters, P. J. Young, C. Agus et al., "Cruciferous vegetable consumption alters the metabolism of the dietary carcinogen 2-amino-1-methyl-6-phenylimidazo[4,5-b]pyridine (PhIP) in humans," Carcinogenesis, vol. 25, no. 9, pp. 1659-1669, 2004.

[40] S. L. Navarro, S. Peterson, C. Chen et al., "Cruciferous vegetable feeding alters UGT1A1 activity: diet- and genotype-dependent changes in serum bilirubin in a controlled feeding trial," Cancer Prevention Research, vol. 2, no. 4, pp. 345-352, 2009.

[41] S. S. Hecht, S. G. Carmella, and S. E. Murphy, "Effects of watercress consumption on urinary metabolites of nicotine in smokers," Cancer Epidemiology Biomarkers and Prevention, vol. 8, no. 10, pp. 907-913, 1999.

[42] M. Decker, M. Arand, and A. Cronin, "Mammalian epoxide hydrolases in xenobiotic metabolism and signalling," Archives of Toxicology, vol. 83, no. 4, pp. 297-318, 2009.

[43] N. Gamage, A. Barnett, N. Hempel et al., "Human sulfotransferases and their role in chemical metabolism," Toxicological Sciences, vol. 90, no. 1, pp. 5-22, 2006.

[44] D. Markovich, "Physiological roles and regulation of mammalian sulfate transporters," Physiological Reviews, vol. 81, no. 4, pp. 1499-1533, 2001.

[45] E. Sim, K. Walters, and S. Boukouvala, "Arylamine N-acetyltransferases: from structure to function," Drug Metabolism Reviews, vol. 40, no. 3, pp. 479-510, 2008.

[46] J. W. Chiao, H. Wu, G. Ramaswamy et al., "Ingestion of an isothiocyanate metabolite from cruciferous vegetables inhibits growth of human prostate cancer cell xenografts by apoptosis and cell cycle arrest," Carcinogenesis, vol. 25, no. 8, pp. 14031408, 2004. 

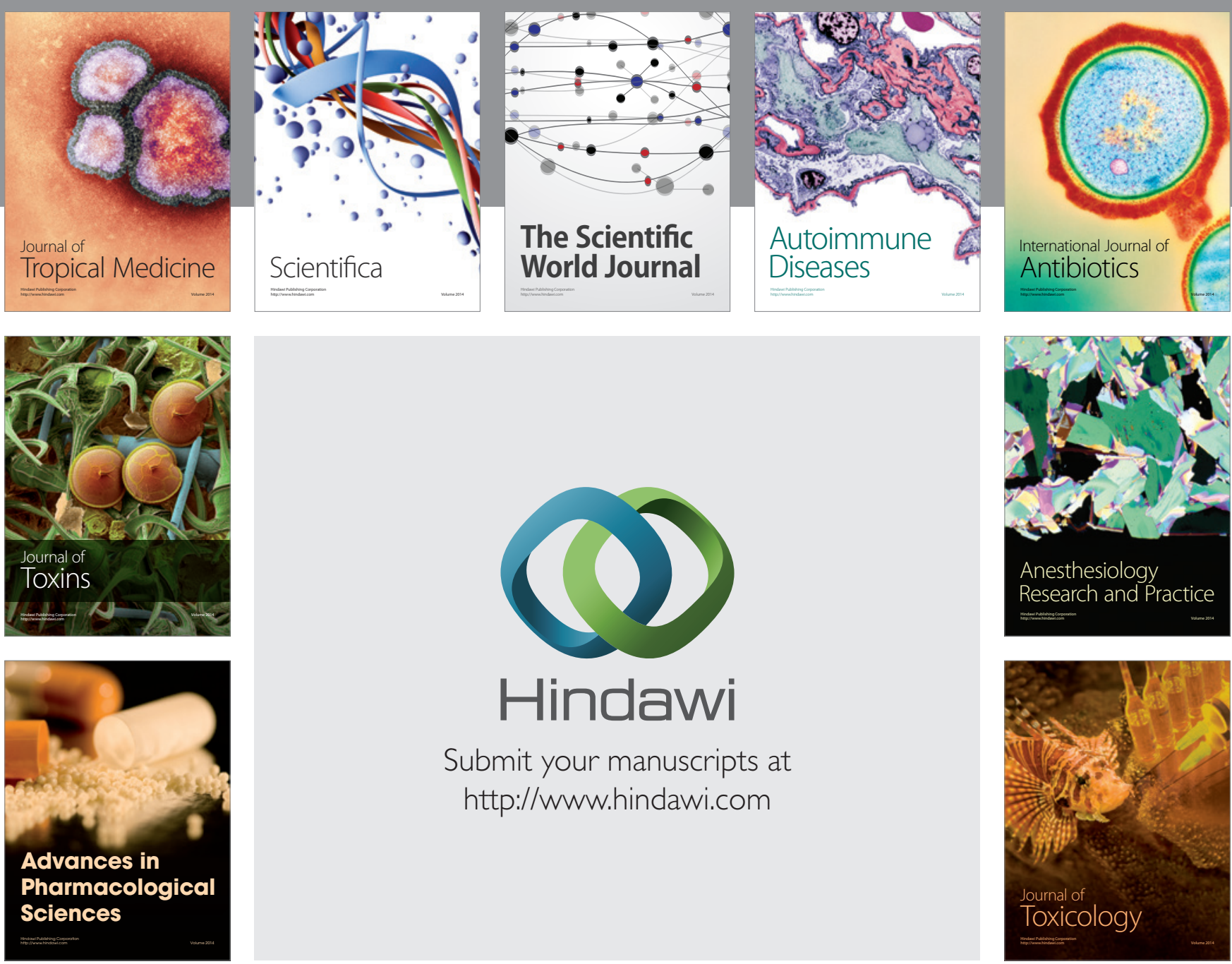

\section{Hindawi}

Submit your manuscripts at

http://www.hindawi.com
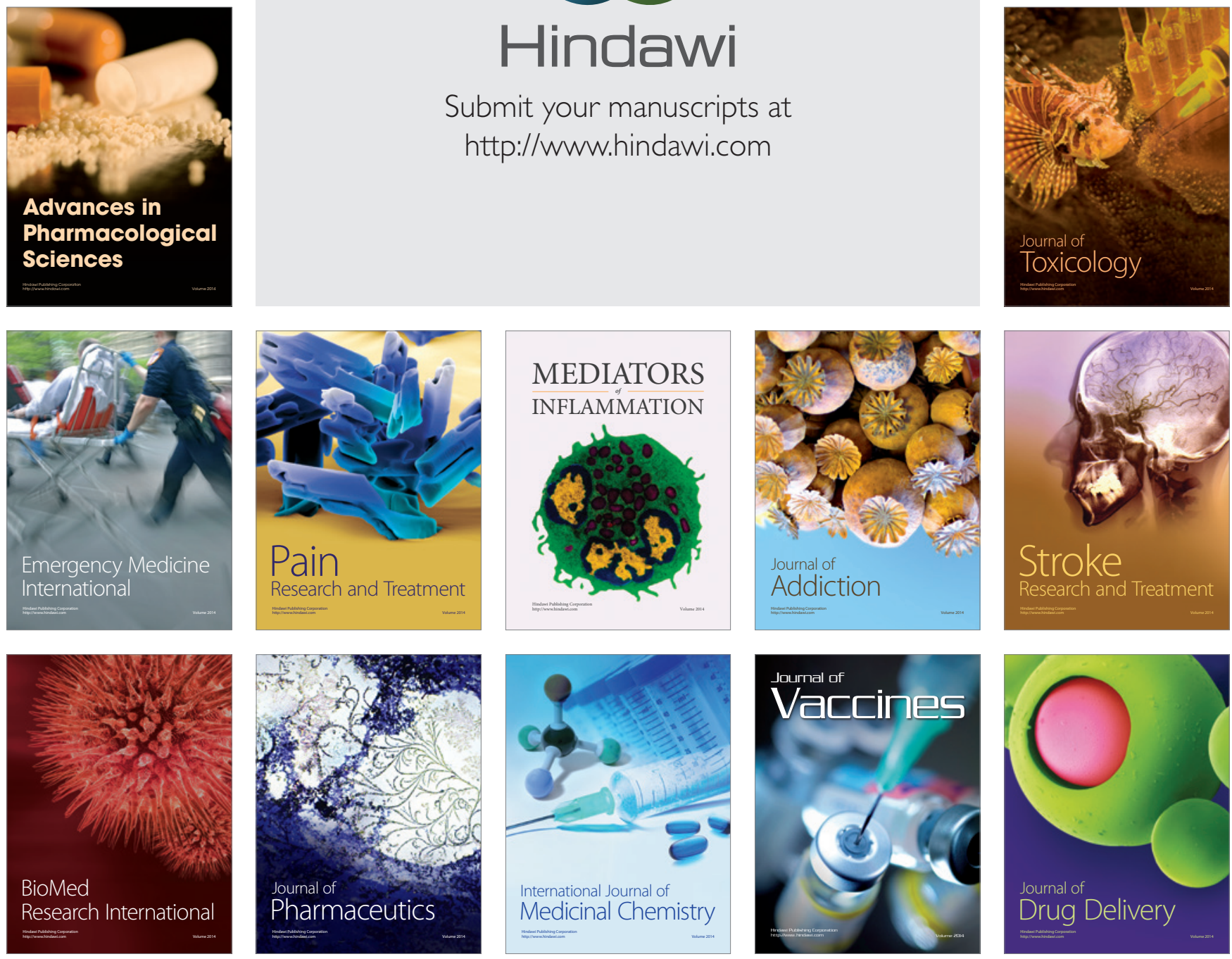